Editorial: Hospital Metropolitano

ISSN (impreso) 1390-2989 - ISSN (electrónico) 2737-6303

Edición: Vol. 28 No 4 (2020) octubre - diciembre

DOI: https://doi.org/10.47464/MetroCiencia/vol28/4/2020/36-41

URL: https://revistametrociencia.com.ec/index.php/revista/article/view/94

Pág: $36-41$

\title{
Interpretación de biomarcadores en pacientes pediátricos con infección por Adenovirus
}

\author{
Interpretation of biomarkers in pediatric patients with \\ Adenovirus infection
}

\author{
María Augusta Molina Huertas' $\left(\mathbb{D}\right.$, Adriana Verónica Arnao Noboa ${ }^{2}$ (D)
}

Pontificia Universidad Católica del Ecuador, Quito, Ecuador

Hospital Metropolitano, Quito, Ecuador ${ }^{2}$

Recibido: 15/08/2020 Aceptado: 18/09/2020 Públicado: 29/10/2020

RESUMEN

Objetivo: Evaluar el uso de los biomarcadores proteína C reactiva (PCR) y procalcitonina (PCT) para la valoración de severidad clínica en pacientes pediátricos diagnosticados con infección por adenovirus. Método: Se estudiaron 100 pacientes mayores de 28 días y menores a 15 años con diagnóstico confirmado de infección por adenovirus, en el Hospital Vozandes Quito, Hospital Metropolitano y Hospital de los Valles en el periodo enero 2010 a mayo 2019 , se recolectó información demográfica y clínica de forma retrospectiva. las características clínicas y biomarcadores se compararon de acuerdo a la severidad de la patología respiratoria presentada, cuya clasificación por requerimientos terapéuticos la definió como leve, moderada y grave. Resultados: El $89 \%$ de los pacientes presentó severidad clínica leve, el 11\% moderada y ninguno fue clasificado como severa. El 35\% de los pacientes presentaron coinfección con al menos un virus adicional, estos presentaron severidad clínica moderada en el 63,3\%. Los valores promedio de PCR fueron 61,3 $\pm 54,06$ mg/L y PCT $0,65 \pm 0,8 \mathrm{ng} / \mathrm{mL}$. Entre los pacientes con severidad clínica leve y moderada vemos que PCR y PCT fueron superiores en pacientes con severidad clínica leve $66,07 \pm 55,09 \mathrm{mg} / \mathrm{L}$ vs $22,71 \pm 19,60 \mathrm{mg} / \mathrm{L}, \mathrm{p}=0,003$ y $0,70 \pm 0,83 \mathrm{ng} / \mathrm{mL}$ vs $0,23 \pm 0,26 \mathrm{ng} / \mathrm{mL}, \mathrm{p}=0.005$ respectivamente. Al momento de predecir la severidad clínica de los pacientes pediátricos diagnosticados con adenovirus el área bajo la curva encontrada en estos dos parámetros fue 0,241 y 0,224 para PCT y PCR respectivamente, con valores de sensibilidad y especificidad bajo el 50\%. Conclusión: Los biomarcadores PCT y PCR presentan limitada utilidad al momento de predecir la severidad clínica de los pacientes pediátricos diagnosticados con infección por adenovirus.

Palabras claves: Infección por adenovirus, proteína C reactiva, procalcitonina, sensibilidad, especificidad.

\section{ABSTRACT}

Objective: To evaluate the use of C-reactive protein (CRP) and procalcitonin (PCT) biomarkers for the assessment of clinical severity in pediatric patients diagnosed with adenovirus infection. Method: 100 patients older than 28 days and younger than 15 years with a confirmed diagnosis of adenovirus infection were studied at the Hospital Vozandes Quito, Hospital Metropolitano and Hospital de los Valles in the period January 2010 to May 2019 , demographic information was collected and retrospectively. the clinical characteristics and biomarkers were compared according to the severity of the respiratory pathology presented, whose classification by therapeutic requirements defined it as mild, moderate and severe. Results: $89 \%$ of the patients presented mild clinical severity, $11 \%$ moderate and none were classified as severe. $35 \%$ of the patients presented coinfection with at least one additional virus, these presented moderate clinical severity in 63.3\%. Mean CRP values were $61.3 \pm 54.06 \mathrm{mg} / \mathrm{L}$ and PCT $0.65 \pm 0.8 \mathrm{ng} / \mathrm{mL}$. Among patients with mild and moderate clinical severity, we see that CRP and PCT were higher in patients with mild clinical severity $66.07 \pm 55.09 \mathrm{mg} / \mathrm{L}$ vs $22.71 \pm 19.60 \mathrm{mg} / \mathrm{L}, \mathrm{p}=0.003 \mathrm{and} 0,70 \pm 0.83 \mathrm{ng} / \mathrm{mL}$ vs 0.23 $\pm 0.26 \mathrm{ng} / \mathrm{mL}, \mathrm{p}=0.005$ respectively. When predicting the clinical severity of pediatric patients diagnosed with adenovirus, the area under the curve found in these two parameters was 0.241 and 0.224 for PCT and CRP, respectively, with sensitivity and specificity values below $50 \%$. Conclusion: PCT and CRP biomarkers have limited usefulness when predicting the clinical severity of pediatric patients diagnosed with adenovirus infection.

Keywords: Adenovirus infection, C-reactive protein, procalcitonin, sensitivity, specificity.

María Augusta Molina Huertas: Adriana Verónica Arnao Noboa:
IDs Orcid

https://orcid.org/0000-0002-2248-7580 https://orcid.org/0000-0002-3926-3049

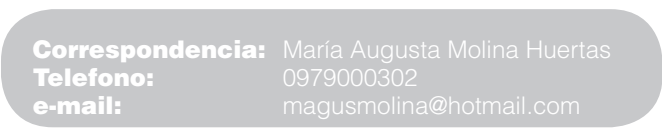




\section{INTRODUCCIÓN}

El adenovirus humano, es un tipo de virus perteneciente a la familia Adenoviridae. Actualmente se reconocen al menos 52 serotipos y 7 especies (Grupo A hasta $G$ ), de los cuales, las especies A, B, C, D y E están relacionadas a brotes infecciosos en humanos siendo las vías respiratorias la región que con más frecuencia es afectada en los procesos infecciosos. Según Linch et al. ${ }^{1}$, la prevalencia hospitalaria descrita, no dista mucho de la prevalencia ajustada en escenarios ambulatorios, en la que se ha descrito que adenovirus es responsable al menos del 5 a $10 \%$ de todas las infecciones respiratorias en pacientes pediátricos.

En general, el espectro clínico encontrado en infecciones por adenovirus varía desde un síndrome similar a influenza hasta complicaciones potencialmente fatales como neumonía. De acuerdo a Sun et al. ${ }^{2}$, en cuanto a síntomas referidos al momento del ingreso, se ha determinado que la tos se presenta en al menos el $83.76 \%$, rinorrea $63.8 \%$, estridor-jadeos en un $15.82 \%$, faringodinia en un $3.4 \%$, además de síntomas extrapulmonares, tales como: conjuntivitis en un $21.6 \%$, vómito, diarrea y dolor abdominal en un $13.71 \%$, convulsiones $3.59 \%$ y rash en un $1.9 \%$, por lo cual, las manifestaciones pueden ser inespecíficas, por lo que, su valoración sindrómica y la ejecución de exámenes específicos permiten confirmar el diagnóstico.

En el proceso diagnóstico luego de la valoración clínica y de sospecha del paciente con infección respiratoria corresponde la valoración de laboratorio y exámenes inmunológicos específicos para el establecimiento de la infección por adenovirus. Dado que los métodos definitivos de diagnóstico para adenovirus son poco disponibles en diversos centros sanitarios y altamente costosos, se ha propuesto el uso de biomarcadores para la valoración de la severidad clínica de la infección y la diferenciación inicial con infección bacteriana, que en consecuencia resultaría una aproximación diagnóstico costo-beneficio favorable ${ }^{3}$.

\section{MATERIALES Y MÉTODOS}

\section{Sujetos}

Se estudiaron 100 pacientes mayores de 28 días y menores a 15 años con diagnóstico confirmado de infección por adenovirus determinada al por análisis de secreción nasofaríngea.

\section{Recolección de datos}

Se recolectó información demográfica y clínica de forma retrospectiva. Se incluyó: edad, días de hospitalización, anamnesis detallada, manifestaciones clínicas respiratorias y no respiratorias, signos vitales completos, examen físico detallado, severidad clínica, biometría hemática, cuantificación de proteína C reactiva y procalcitonina.

\section{Análisis Estadístico}

El análisis estadístico se realizó en el programa SPSS v25. El nivel de confianza se fijó en el 95\%. Los datos clínicos y de laboratorio se expresaron como media \pm desviación estándar (DE) o porcentajes. Se utilizó el Chi cuadrado y el test exacto de Fisher para comparar variables cualitativas. Se empleó el test de Kolmogorov-Smirnov para determinar la normalidad de la distribución y utilizar $t$ Student para comparar las variables con distribución normal y U Mann-Whitney en caso contrario. Para valorar los biomarcadores se realizó un análisis con curva ROC (Característica Operativa del Receptor) y se obtuvieron los valores de Área bajo la Curva (AUC).

\section{RESULTADOS}

El género predominante fue el masculino con el 56\% de la muestra. Los pacientes fueron clasificados según su grupo etario en 5 grupos, mayoritariamente la población fue de preescolares con el 54\%. La ubicación de la infección se fracciona entre infecciones respiratorias superiores e inferiores con el $43 \%$ y $47 \%$ respectivamente, un $10 \%$ adicional se clasifica como sistémica. Las características clínicas y de laboratorio se muestran en la Tabla 1 .

Tabla 1. Características de los pacientes con adenovirus

\begin{tabular}{|c|c|c|c|}
\hline & & $\begin{array}{l}\text { Frecuencia } \\
(\mathrm{N}=100)\end{array}$ & $\begin{array}{c}\text { Porcentaje } \\
\text { (\%) }\end{array}$ \\
\hline \multirow{2}{*}{ GÉNERO } & FEMENINO & 46 & 46,0 \\
\hline & MASCULINO & 54 & 54,0 \\
\hline \multirow{5}{*}{ GRUPO ETARIO } & $\begin{array}{l}\text { LACTANTE } \\
\text { MENOR }\end{array}$ & 4 & 4,0 \\
\hline & $\begin{array}{l}\text { LACTANTE } \\
\text { MAYOR }\end{array}$ & 15 & 15,0 \\
\hline & PREESCOLAR & 54 & 54,0 \\
\hline & ESCOLAR & 25 & 25,0 \\
\hline & ADOLESCENTE & 2 & 2,0 \\
\hline \multirow{5}{*}{$\begin{array}{l}\text { MANIFESTACIONES } \\
\text { CLÍNICAS }\end{array}$} & $\begin{array}{c}\text { RUIDOS } \\
\text { PULMONARES }\end{array}$ & 32 & 32,0 \\
\hline & RINORREA & 50 & 50,0 \\
\hline & TOS & 69 & 69,0 \\
\hline & $\begin{array}{c}\text { CONGESTIÓN } \\
\text { NASAL }\end{array}$ & 36 & 36,0 \\
\hline & & Media & $\mathrm{DE}$ \\
\hline \multirow[t]{2}{*}{ SIGNOS VITALES } & $\begin{array}{l}\text { TEMPERATURA } \\
\left({ }^{\circ} \mathrm{C}\right)\end{array}$ & 38,6 & 0,96 \\
\hline & SATURACION (\%) & 89 & 9 \\
\hline \multirow{3}{*}{$\begin{array}{l}\text { EXÁMENES DE } \\
\text { LABORATORIO }\end{array}$} & LEUCOCITOS & 11946 & 5293 \\
\hline & PCR (mg/L) & 61,30 & 54,06 \\
\hline & РCT (ng/mL) & 0,65 & 0,80 \\
\hline
\end{tabular}


El 89\% de los pacientes presentó severidad clínica leve, el $11 \%$ moderada y ninguno fue clasificado como severa. El $70 \%$ de los pacientes atendidos en emergencia positivos para Adenovirus fueron hospi-

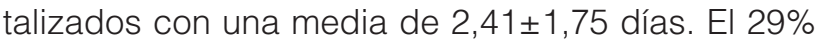
fue dado de alta hacia su domicilio y la estancia promedio en emergencia fue 190,3 $\pm 66,64$ minutos. Un solo paciente fue ingresado a la unidad de cuidados intensivos pediátricos a pesar de no cumplir criterios para hospitalización en dicha área.

Al analizar la frecuencia de coexistencia entre Adenovirus y otros virus respiratorios se encontró que el $35 \%$ de los pacientes presentaron coinfección con al menos 1 virus adicional. La coinfección más frecuente es con Rinovirus (20\%). Otros virus se presentaron con menor frecuencia: Influenza A en el 6\% de la población, VSR en el $5 \%$, Parainfluenza en el $4 \%$, Metaneumovirus, Influenza B y Coronavirus en el $3 \%$.

Se realizó la comparación de las diferentes variables demográficas, clínicas y de laboratorio entre los pacientes que presentaron severidad clínica leve $(n=89)$ y moderada $(n=11)$ a fin de buscar diferencias entre estos dos grupos. Se observó que en los pacientes con severidad moderada se presentaron con mayor frecuencia ruidos pulmonares anormales y tos. Los diagnósticos más frecuentes en los pacientes con severidad clínica moderada fueron la neumonía y la bronconeumonía, además, presentaron con mayor frecuencia coinfección con al menos un virus adicional al adenovirus y estuvieron hospitalizados por más días. La variabilidad en la cuantificación de los biomarcadores PCR, PCT y de los leucocitos entre los pacientes con severidad clínica leve y moderada muestra que se presentan cifras superiores de estos tres marcadores en aquellos individuos con infección leve. Tabla 2.

Tabla 2. Características según severidad clínica en pacientes con adenovirus

\begin{tabular}{|c|c|c|c|c|}
\hline \multirow{4}{*}{$\begin{array}{l}\text { MANIFESTACIONES } \\
\text { CLIINICAS }\end{array}$} & & \multicolumn{2}{|c|}{ SEVERIDAD CLÍNICA } & \multirow[b]{2}{*}{$\begin{array}{l}\text { Valor } \\
\text { de } p\end{array}$} \\
\hline & & $\begin{array}{c}\text { LEVE } \\
(\mathrm{N}=89) \\
\mathrm{n}(\%)\end{array}$ & $\begin{array}{c}\text { MODERADA } \\
(\mathrm{N}=11) \\
\mathrm{n}(\%)\end{array}$ & \\
\hline & $\begin{array}{l}\text { Ruidos } \\
\text { Pulmonares }\end{array}$ & $22(24,7)$ & $10(90,9)$ & 0,00 \\
\hline & Tos & $58(65,2)$ & $11(100)$ & 0,01 \\
\hline \multirow{2}{*}{ DIAGNÓSTICOS } & Neumonía & $30(33,7)$ & $8(72,7)$ & 0,01 \\
\hline & Bronconeumonía & $3(3,4)$ & $3(27,3)$ & 0,01 \\
\hline $\begin{array}{l}\text { PRESENCIA DE } \\
\text { COINFECCIÓN }\end{array}$ & $\begin{array}{c}\text { Coinfección } \\
\text { Viral }\end{array}$ & $28(31,5)$ & $7(63,6)$ & 0,04 \\
\hline \multirow[t]{2}{*}{ EVOLUCIÓN } & $\begin{array}{l}\text { Estancia En } \\
\text { Emergencia } \\
\text { (Minutos), } \\
\text { Media (De) }\end{array}$ & $\begin{array}{l}193,03 \\
(66,78)\end{array}$ & $\begin{array}{l}168,18 \\
(64,16)\end{array}$ & 0,24 \\
\hline & $\begin{array}{l}\text { Hospitalización } \\
\text { (Días), Media } \\
\text { (De) }\end{array}$ & $\begin{array}{c}2,18 \\
(1,61)\end{array}$ & $4,27(1,73)$ & 0,00 \\
\hline
\end{tabular}

\begin{tabular}{|c|c|c|c|c|}
\hline $\begin{array}{c}\text { USO DE } \\
\text { ANTIBIÓTICOS }\end{array}$ & Antibioticoterapia & $44(49,4)$ & $7(63,6)$ & 0,37 \\
\hline \multirow{3}{*}{$\begin{array}{l}\text { EXÁMENES DE } \\
\text { LABORATORIO }\end{array}$} & $\begin{array}{l}\text { Leucocitos, } \\
\text { Media (DE) }\end{array}$ & $\begin{array}{l}12099 \\
(5390)\end{array}$ & $\begin{array}{l}10703 \\
(4447)\end{array}$ & 0,35 \\
\hline & $\begin{array}{l}\text { PCR (mg/L), } \\
\text { Media (DE) }\end{array}$ & $\begin{array}{l}66,07 \\
(55,09)\end{array}$ & $\begin{array}{c}22,71 \\
(19,60)\end{array}$ & 0,003 \\
\hline & $\begin{array}{l}\text { PCT (ng/mL), } \\
\text { Media (DE) }\end{array}$ & $\begin{array}{c}0,70 \\
(0,83)\end{array}$ & $0,23(0,26)$ & 0,005 \\
\hline
\end{tabular}

DE: desviación estándar, PCR: proteína C reactiva, PCT: procalcitonina

Se analizó la variabilidad en la cuantificación de los biomarcadores PCR, PCT y de los leucocitos entre los pacientes con coinfección viral $(n=35)$ y los pacientes que únicamente mostraron infección con adenovirus ( $n=65$ ), se encontró que los tres marcadores presentaron valores superiores en los pacientes que presentaron adenovirus como infección única. Tabla 3.

Tabla 3. Características de laboratorio según coinfección viral en pacientes con adenovirus

\begin{tabular}{cccc} 
& \multicolumn{2}{c}{ INFECCIÓN } & \\
\cline { 2 - 3 } VARIABLE & $\begin{array}{c}\text { ADENOVIRUS } \\
\text { (N=65) Media } \\
\text { (DE) }\end{array}$ & $\begin{array}{c}\text { COINFECCIÓN } \\
\text { (N=35) Media (DE) }\end{array}$ & $\begin{array}{l}\text { Valor } \\
\text { de } p\end{array}$ \\
\hline LEUCOCITOS & $12337(5198)$ & $11219(5466)$ & 0,32 \\
PCR $(\mathrm{mg} / \mathrm{L})$ & $66,02(51,04)$ & $52,53(59,02)$ & 0,01 \\
PCT $(\mathrm{ng} / \mathrm{mL})$ & $0,75(0,87)$ & $0,45(0,60)$ & 0,05 \\
\hline
\end{tabular}

DE: desviación estándar, $\mathrm{PCR}$ : proteína $\mathrm{C}$ reactiva, PCT: procalcitonina

En los pacientes a quienes se administró antibioticoterapia se evidencian valores superiores de leucocitos, PCR y PCT. Tabla 4.

Tabla 4. Características de laboratorio según terapia antibiótica en pacientes con adenovirus.

\begin{tabular}{cccc} 
& \multicolumn{2}{c}{ ANTIBIOTICOTERAPIA } & Valor \\
\cline { 2 - 3 } VARIABLE & $\mathbf{S I}(\mathbf{N}=\mathbf{5 1})$ & $\begin{array}{c}\text { COINFECCIÓN } \\
\mathbf{( N = 3 5 )} \text { Media (DE) }\end{array}$ & de $p$ \\
\hline LEUCOCITOS & $12730(5976)$ & $117129(4387)$ & 0,12 \\
PCR $(\mathrm{mg} / \mathrm{L})$ & $71,43(60,70)$ & $50,76(44,36)$ & 0,08 \\
PCT $(\mathrm{ng} / \mathrm{mL})$ & $0,89(0,99)$ & $0,40(0,40)$ & 0,03 \\
\hline
\end{tabular}

Se realizó un análisis con curva ROC para evaluar el rendimiento de predicción de usar los marcadores inflamatorios PCR y PCT para predecir la severidad clínica de los pacientes pediátricos diagnosticados con adenovirus. Ninguna de las dos pruebas presentó una capacidad discriminatoria diagnóstica mejor que el azar, pues ninguna de las dos presento un área bajo la curva superior al 0,5. Sin embargo, el mejor rendimiento se observó en la PCT, con un área bajo la curva (AUC) de 0,241 [Intervalo de Confianza (IC) al 95\%, 0,092-0,0391]. El punto de corte óptimo para predecir la severidad clínica fue $0,17 \mathrm{ug} / \mathrm{mL}$ con una sensibilidad del $23 \%$ y una especificidad 
del 55\%. La PCR presentó un rendimiento similar con un área bajo la curva (AUC) de 0,224 [Intervalo de Confianza (IC) al 95\%, 0,101-0,347]. El punto de corte óptimo para predecir la severidad clínica fue $19,15 \mathrm{mg} / \mathrm{L}$ con una sensibilidad del $20 \%$ y una especificidad del 46\%. Ilustración 1.

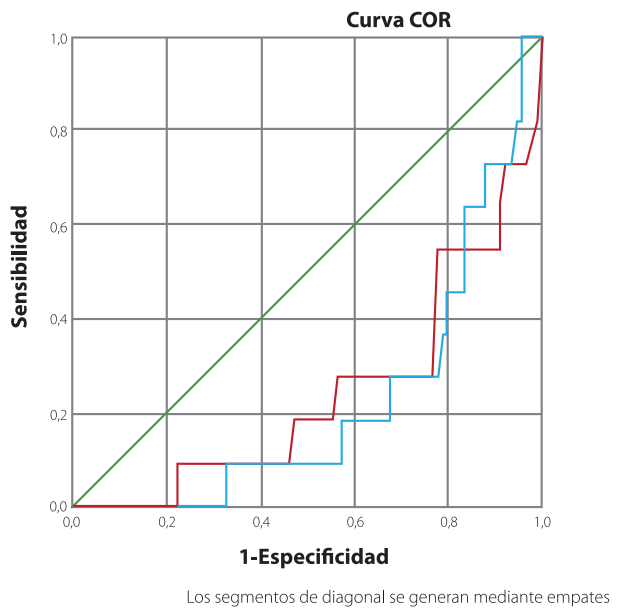

Origen de la curva - PCR $(\mathrm{mg} / \mathrm{L})$
$-P C T(\mathrm{ng} / \mathrm{mL})$ - Línea de referencia

Ilustración 1. Curva ROC de los parámetros de laboratorio utilizados para comparar severidad clínica leve y moderada en pacientes con Adenovirus

Fuente: Los autores

\section{DISCusıón}

Los biomarcadores son análisis de laboratorio cada vez más accesibles en el ámbito hospitalario y en los cuales el médico basa muchas veces su accionar al momento de tratar a los pacientes que se presentan con alguna infección, sin embargo, su utilidad en una patología viral es un tema que se encuentra en discusión pues no siempre cuantificaciones elevadas de estos biomarcadores se correlacionan con una severidad clínica grave o con la presencia de coinfección bacteriana.

Se han reportado niveles elevados de biomarcadores inflamatorios como PCR y PCT en pacientes con infección por adenovirus ${ }^{4,5}$. En el presente estudio se mostraron los siguientes valores; los leucocitos presentaron una media de $11960 \pm 5293$, los valores de PCR fueron $61,3 \pm 54,06 \mathrm{mg} / \mathrm{L}$ y PCT 0,65 \pm 0,8 $\mathrm{ng} /$ $\mathrm{mL}$. En el estudio desarrollado por Sun et al. identificaron medias de 7650 para los leucocitos, 47,21 $\pm 33,87$ para la PCR y $0,23 \pm 0,56$ para la $\mathrm{PCT}^{2}$, mientras que en un estudio desarrollado por Jin et al, los leucocitos presentaron una media de 15,100 \pm 8,240 , la PCR 4,88 $\pm 5,32 \mathrm{mg} / \mathrm{L}$ y la PCT 1,65 $\pm 2,11$ $\mathrm{ng} / \mathrm{mL}$ lo que muestra la gran variabilidad de estos marcadores en los distintos estudios ${ }^{6}$. Sin embargo, existe un consenso en afirmar que la infección por adenovirus cursa con niveles elevados de leucocitos y PCR.
Respecto a los valores de PCT existen discrepancias, Elenius et al. describen que los niveles de PCT permanecen bajo el nivel de 0,5 ng/mL en los pacientes con adenovirus ${ }^{7}$. Por otro lado, en el estudio desarrollado por Kunze en 2016, el 42\% de la población de estudio presentó niveles de PCT superiores a $0,5 \mathrm{ng} / \mathrm{mL}$ con una media de $0.75 \mathrm{ng} / \mathrm{mL}^{5}$. Laveglia et al. ${ }^{8}$, reportaron un $70 \%$ de la población con niveles de PCT superiores a $0,5 \mathrm{ng} / \mathrm{mL}$ con una media de $1,14 \mathrm{ng} / \mathrm{mL}$, valores que concuerdan con los resultados de este estudio donde la media de PCT fue $0,65 \pm 0,8 \mathrm{ng} / \mathrm{mL}$

La presencia de coinfección viral es un factor que determina los niveles de PCR y PCT, en este estudio los pacientes con infección única por adenovirus presentaron niveles superiores de estos biomarcadores en comparación con los pacientes con coinfección viral, PCR 66,02 $\pm 51,04 \mathrm{mg} / \mathrm{L}$ vs 52,53 $\pm 59,02 \mathrm{mg} / \mathrm{L}$ respectivamente, $p=0,01$ y PCT $0,75 \pm 0,87 \mathrm{ng} / \mathrm{mL}$ vs $0,45 \pm 0,60 \mathrm{ng} / \mathrm{mL}, p=0,05$. Estos resultados se podrían explicar por el hecho de que la coinfección viral más frecuente fue con rinovirus y se ha reportado valores inferiores de leucocitos y PCR en pacientes con esta infección en comparación con adenovirus ${ }^{9}$. Además, Calvo et al. ${ }^{10}$, en su estudio en población española muestran que los pacientes con infección por adenovirus presentaron valores superiores de leucocitos y PCR en comparación con otras infecciones virales, correspondiéndose con el hecho de que la coinfección viral genere niveles inferiores de biomarcadores en la población del presente estudio.

Al comparar los valores de los biomarcadores entre los pacientes con severidad clínica leve y moderada vemos que tanto la PCR como la PCT muestran valores superiores en pacientes con severidad clínica leve, este hallazgo podría responder al hecho de que la mayoría de los pacientes con clasificación clínica leve son individuos con infección única por adenovirus. Apenzeller et al. ${ }^{10}$, concluyen que la infección por adenovirus está asociada con valores elevados de PCR independiente de la severidad y duración de la enfermedad. Según Cheng et al. ${ }^{11}$, la presencia de valores elevados de leucocitos y PCR puede implicar la presencia de una infección viral como adenovirus y no necesariamente una infección bacteriana. En el estudio desarrollado por Kunze en 2016, el $42 \%$ de la población de estudio presentó niveles de PCT superiores a 0,5ug/L sin embargo no se presentaron diferencias significativas al comparar estos valores con la severidad clínica de los pacientes $^{5}$. Como vemos no existen certezas en cuanto a la relación de los valores de PCT y la severidad de la infección por adenovirus.

La limitada utilidad de los biomarcadores PCT y PCR al momento de predecir la severidad clínica de los pacientes pediátricos diagnosticados con adenovirus se corrobora con el área bajo la curva encontra- 
da en estos dos parámetros 0,241 y 0,224 para PCT y PCR respectivamente, con valores de sensibilidad y especificidad bajo el 50\%. Estos resultados indican que ambas pruebas no son útiles para predecir la severidad clínica de los pacientes pediátricos diagnosticados con adenovirus. Sun et al. al buscar la utilidad de la PCR y PCT para predecir la progresión a neumonía severa en pacientes con adenovirus, muestran que la PCR presenta un área bajo la curva cercana a 0,5 por lo que no es sensible ni especifica al momento de realizar esta distinción, sin embargo, la PCT presenta un área bajo la curva de 0,65 , con un punto de corte de $0,35 \mathrm{ng} / \mathrm{mL}$, una sensibilidad del $81 \%$ y especificidad del $51 \%$, además afirman que las concentraciones de interleucina 6 y velocidad de sedimentación globular están asociadas con la severidad de la infección respiratoria por adenovirus ${ }^{3}$.

\section{CONCLUSIONES}

La infección por adenovirus se asociaron con valores elevados de PCR $(61,3 \pm 54,06 \mathrm{mg} / \mathrm{L})$ y PCT $(0,65 \pm 0,8 \mathrm{ng} / \mathrm{mL})$, sin embargo los niveles fueron superiores en pacientes con severidad leve PCR $(66,07 \pm 55,09 \mathrm{mg} / \mathrm{L})$ PCT $(0,70 \pm 0,83)$, en comparación de pacientes con severidad moderada PCR $(22,71 \pm 19,60 \mathrm{mg} / \mathrm{L})$ PCT $(0,23 \pm 0,26 \mathrm{ng} / \mathrm{mL})$, por lo que la detección de cuantificaciones elevadas de biomarcadores en pacientes pediátricos con infección por adenovirus no necesariamente debe asociarse con infecciones graves, presentando así una limitada utilidad al momento de predecir la severidad clínica.

\section{CONTRIBUCIÓN DE LOS AUTORES}

María Augusta Molina Huertas: Concepción y diseño del trabajo; recolección y obtención de resultados; análisis e interpretación de datos; redacción del manuscrito.

Adriana Verónica Arnao Noboa: Concepción y diseño del trabajo; recolección y obtención de resultados; análisis e interpretación de datos; redacción del manuscrito.

\section{CONFLICTO DE INTERESES}

Los autores declararon no tener ningún conflicto de interés personal, financiero, intelectual, económico y de interés corporativo con el Hospital Metropolitano y los miembros de la revista MetroCiencia.

\section{FINANCIAMIENTO}

El financiamiento para la realización de la presente investigación fue financiado por los autores.

\section{REFERENCIAS BIBLIOGRÁFICAS}

1. Lynch J, Fishbein M, Echavarria M. Adenovirus. Semin Respir Crit Care Med. [Internet] 2011 [consultado 2020 Oct 03];32(4):494-511. Disponible en: https://www.thieme-connect.com/products/ejournals/ abstract/10.1055/s-0031-1283287 DOI: 10.1055/s-0031-1283287

2. Sun Q, Jiang W, Chen Z, Huang L, Wang Y, Huang F, Ji W, Zhang X, Shao $X$, Yan $Y$. Epidemiology and clinical features of respiratory adenoviral infections in children. Eur J Pediatr. [Internet] 2014 [consultado 2020 Oct 03];173(4):441-4. Disponible en: https://pubmed.ncbi. nIm.nih.gov/24169730/ DOI: 10.1007/s00431-013-2188-z

3. Ferone EA, Berezin EN, Durigon GS, Finelli C, Felício MCC, Storni $J G$, et al. Clinical and epidemiological aspects related to the detection of adenovirus or respiratory syncytial virus in infants hospitalized for acute lower respiratory tract infection. J Pediatr (Rio J). [Internet] 2014 [consultado 2020 Oct 03];90(1):42-9. Disponible en: https:// www.scielo.br/pdf/jped/v90n1/0021-7557-jped-90-01-00042.pdf DOI: dx.doi.org/10.1016/j.jped.2013.05.005

4. Viaño P, Moral A, Tomé I, Sánchez M, Villalobos E, Bascuas M, Ecclesia F. Adenovirus infections that require hospital admission: epidemiology, laboratory findings and approach. Revista Pediatría Atención Primaria. [Internet] 2019 [consultado 2020 Oct 03];21(1):149-57. Disponible en: https://pap.es/article/12804/adenovirus-infections-that-require-hospital-admission-epidemiology-laboratory-findings-and-approach

5. Kunze W. Predictive value of procalcitonin in respiratory adenovirus infections in children with elevated C-reactive protein levels. WebmedCentral Paediatr. [Internet] 2016 [consultado 2020 Oct 03];7(12):14. Disponible en: https://www.webmedcentral.com/wmcpdf/Article_ WMC005238.pdf

6. Jin Y, Zhang RF, Xie ZP, Yan KL, Gao HC, Song JR, et al. Prevalence of adenovirus in children with acute respiratory tract infection in Lanzhou, China. Virol Journal. [Internet] 2013 [consultado 2020 Oct 03];10:1-8. Disponible en: https://virologyj.biomedcentral.com/articles/10.1186/1743-422X-10-271

7. Elenius V, Peltola V, Ruuskanen O, Ylihärsilä M, Waris M. Plasma procalcitonin levels in children with adenovirus infection. Arch Dis Child. [Internet] 2012 [consultado 2020 Oct 03];97(6):582-3. Disponible en: https://pubmed.ncbi.nlm.nih.gov/22190671/ DOI: 10.1136/archdischild-2011-301308

8. Laveglia V, Gorina N, Cassanello P. Adenovirus infection: beware of plasma procalcitonin levels in children. Arch Dis Child. [Internet] 2018 [consultado 2020 Oct 03];103(6):622-3. Disponible en: https://pubmed.ncbi.nlm.nih.gov/29208593/ DOI: 10.1136/archdischild-2017-314307

9. Esposito S, Zampiero A, Bianchini S, Mori A, Scala A, Tagliabue C, Sathya C, Fossali E, Piralla A, Principi N. Epidemiology and Clinical Characteristics of Respiratory Infections Due to Adenovirus in Children Living in Milan, Italy, during 2013 and 2014. PLoS One. [Internet] 2016 [consultado 2020 Oct 03];11(4):1-13. Disponible en: https://journals. plos.org/plosone/article/file?id=10.1371/journal. pone.0152375\&type=printable DOI:10.1371/journal.pone. 0152375

10. Calvo C, García M, Sanchez R, Román C, Tabares A, Pozo F, Casas I. Eight year prospective study of adenoviruses infections in hospitalized children. Comparison with other respiratory viruses. PLoS One. [Internet] 2015 [consultado 2020 Oct 03];10(7): 1-10. Disponible en: https://journals.plos.org/plosone/article/file?id=10.1371/journal.pone.0132162\&type $=$ printable DOI:10.1371/journal . pone.0132162

11. Cheng J, Peng C, Chiu N, Weng L, Chiu Y, Chang L, Tsung-Ning D Huang F, Liu C, Chi H. Risk factor analysis and molecular epidemiology of respiratory adenovirus infections among children in northern Taiwan, 2009-2013. Journal of Microbiology, Immunology and Infection. [Internet] 2017 [consultado 2020 Oct 03];50(4):418-26. Disponible en: https://core.ac.uk/download/pdf/82712647.pdf DOI: dx.doi. org/10.1016/j.jmii.2015.08.006

12. Appenzeller, C., Ammann, R. A., Duppenthaler, A., Gorgievski-Hrisoho, M., \& Aebi, C. (2002). Serum C-reactive protein in children with adenovirus infection. Swiss Medical Weekly, 132(25-26), 345-350.

13. Barnadas, C., Schmidt, D. J., Fischer, T. K., \& Fonager, J. (2018). Molecular epidemiology of human adenovirus infections in Denmark, 2011-2016. Journal of Clinical Virology, 104(January 2018), 16-22. https://doi.org/10.1016/j.jcv.2018.04.012

14. Berce, V., Unuk, S., Duh, D., Homšak, M., \& Vičič, M. (2015). Clinical and laboratory characteristics of viral lower respiratory tract infections 
in preschool children. Wiener Klinische Wochenschrift, 127, 255-262. https://doi.org/10.1007/s00508-015-0843-2

15. Couderc, R., Mary, R., \& Veinberg, F. (2004). Marcadores de inflamación en pediatría. Acta Bioquimica Clinica Latinoamericana, 38(4), 513-517.

16. Cowling, B. J., Chan, K. H., \& Peiris, J. S. (2018). Influenza-like illness and viral aetiology in Hong Kong children. Hong Kong Medical Journal = Xianggang Yi Xue Za Zhi, 24(5), 12-15.

17. Ferone, E. A., Berezin, E. N., Durigon, G. S., Finelli, C., Felício, M. C C., Storni, J. G.

18. Oliveira, D. B. L. D. (2014). Clinical and epidemiological aspects related to the detection of adenovirus or respiratory syncytial virus in infants hospitalized for acute lower respiratory tract infection. Jornal de Pediatria, 90(1), 42-49. https://doi.org/10.1016/j.jped.2013.05.005

19. Foong Ng, K., Kee Tan, K., Hong Ng, B., Nair, P., \& Ying Gan, W. (2015). Epidemiology of adenovirus respiratory infections among hospitalized children in Seremban, Malaysia. Transactions of the Royal Society of Tropical Medicine and Hygiene, 109(7), 433-439. https:// doi.org/10.1093/trstmh/trv042
20. 19. Haque, E., Banik, U., Monwar, T., Anthony, L., \& Adhikary, A. K. (2018). Worldwide increased prevalence of human adenovirus type 3 (HAdV-3) respiratory infections is well correlated with heterogeneous hypervariable regions (HVRs) of hexon. PLoS ONE, 13(3), https://doi. org/10.1371/journal.pone.0194516

21. Kendall Scott, M., Chommanard, C., Lu, X., Appelgate, D., Grenz, L., Schneider, E., ...Thomas, A. (2016). Human adenovirus associated with severe respiratory infection, Oregon, USA, 2013-2014. Emerging Infectious Diseases, 22(6), 1044-1051. https://doi.org/10.3201/ eid2206.151898

22. Kenmoe, S., Vernet, M.-A., Le Goff, J., Penlap, V. B., Vabret, A., \& Njouom, R. (2018). Molecular characterization of human adenovirus associated with acute respiratory infections in Cameroon from 2011 to 2014. Virology Journal, 15(1), 1-7. https://doi.org/10.1186/s12985018-1064-X

23. Khanal, S., Ghimire, P., \& Dhamoon, A. (2018). The Repertoire of Adenovirus in Human Disease: The Innocuous to the Deadly. Biomedicines, 6(1), 30. https://doi.org/10.3390/biomedicines6010030 